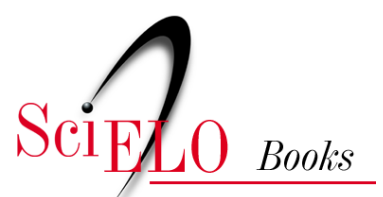

\title{
2. Congressos da Abrasco: a expressão de um espaço construido Soraya Almeida Belisário
}

\section{SciELO Books / SciELO Livros / SciELO Libros}

BELISÁRIO, S. A. Congressos da Abrasco: a expressão de um espaço construido. In: LIMA, N. T., and SANTANA, J. P., ed s. Saúde coletiva como compromisso: a trajetória da Abrasco [online]. Rio de Janeiro: Editora FIOCRUZ; Abrasco, 2006, pp. 45-78. ISBN: 978-65-5708-156-3. https://doi.org/10.7476/9786557081563.0003.

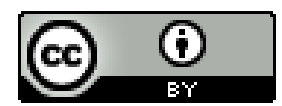

All the contents of this work, except where otherwise noted, is licensed under a Creative Commons Attribution 4.0 International license.

Todo o conteúdo deste trabalho, exceto quando houver ressalva, é publicado sob a licença $\underline{\text { Creative Commons }}$ Atribição 4.0.

Todo el contenido de esta obra, excepto donde se indique lo contrario, está bajo licencia de la licencia $\underline{\text { Creative }}$ Commons Reconocimento 4.0. 


\title{
2 Congressos da Abrasco: A eXPREsSÃo de UM ESPAÇO CONSTRUÍDO ${ }^{1}$
}

Soraya Almeida Belisário

\begin{abstract}
$\mathbb{P}_{\text {ode-se definir congresso como reunião, encontro, ligação, }}$ ajuntamento, conferência, assembléia de delegados para discutirem assuntos de importância (Ferreira, 1986). Nesses encontros, uma associação científica tem, por sua vez, a possibilidade de divulgação de sua produção científica, de difusão de conhecimentos e de troca de experiências. Uma instituição com as características da Associação Brasileira de Pós-Graduação em Saúde Coletiva (Abrasco) tem nesses momentos, além dos componentes apontados, momentos de tensões, de demonstração de especificidades, de proposições políticas, pelo fato de seus congressos se constituírem como fóruns de dimensão nacional e até mesmo internacional de discussão e de formulação de políticas de saúde (Belisário, 2002).

Com uma surpreendente capacidade convocatória e mobilizadora, além de uma vocalização de dimensões extraordinárias, os congressos promovidos pela Abrasco, ao longo de seus 25 anos, vêm surpreendendo até os mais pessimistas. Desde o primeiro evento patrocinado por ela, observa-se não só a crescente participação dos profissionais do setor como também a diversidade de temas e objetos de discussão e análise.

O grande papel desempenhado pelos congressos da Abrasco na área científica - assim como sua vocação de disseminação de conhecimentos
\end{abstract}

\footnotetext{
' Este texto é uma versão revista e atualizada de capítulo integrante da tese de doutorado Associativismo em Saúde Coletiva: um estudo da Associação Brasileira de Saúde Coletiva - Abrasco, defendida na Universidade Estadual de Campinas (Unicamp), em 2002, pela autora (Belisário, 2002).
} 
e estímulo para que se produzam trabalhos científicos também com base em experiências práticas dos serviços de saúde - é constatado por meio do crescente número de trabalhos apresentados, detentores dos mais diversos matizes (Belisário, 2002). São eventos de inegável força e notória importância, já que, a despeito de conjunturas mais ou menos favoráveis, a Abrasco mantém sua capacidade de convocação e sua legitimidade, representadas tanto pelo crescente número de participantes como pela presença em seus congressos das mais diversas autoridades, como ministros de Estado, prefeitos, secretários e gestores, dentre outros. A análise desses eventos constitui importante fonte de entendimento da dinâmica da associação, de sua crescente legitimidade, do crescimento de suas diversas áreas científicas e de seu poder de representação.

Em sua trajetória como instituição científica, a especificidade e a densidade do conhecimento, aliadas ao crescimento e à afirmação de certas áreas da Saúde Coletiva - crescimento esse decorrente da complexidade e da diversidade do campo -, vão impor mudanças na sistemática de realização dos congressos da associação, levando à promoção de eventos específicos por áreas.

Observa-se que, desde seus primeiros momentos, a Abrasco inaugurou a prática de realizar reuniões temáticas, parciais, no intuito de discutir as questões mais prementes do campo que então se constituía. Contudo, a crescente diversidade e a complexidade de áreas e temáticas, a serem abordadas no campo da Saúde Coletiva (SC), mostraram logo a necessidade de se pensar uma fórmula mais abrangente e participativa. Impulsionada por essa necessidade, a Abrasco inaugurou sua nova fórmula de encontro, de interlocução com seus representados, o 'Abrascão'.

Em seu percurso científico-político, no qual se destaca sua capacidade convocatória, a Abrasco vem, ao longo dos anos, desenvolvendo seu próprio know-how na organização não só de congressos, seus eventos maiores, como também de uma série de encontros e seminários, chegando a ter uma importante atuação como grupo organizado nos mais variados eventos da vida nacional.

Constituindo-se efetivo espaço de representação da comunidade da SC, as mudanças de enfoque e amplitude sofridas pelo 'Abrascão', ao longo dos anos, têm na conjuntura social, política e científica as prováveis razões de sua existência, reflexo também dos diversos momentos vivenciados pela própria associação.

$\mathrm{Na}$ análise do tema central escolhido para nortear cada 'Abrascão', observa-se que ele parte de uma 'aguerrida' postura política, em consonância com a conjuntura político-social do país, e caminha em direção a temas 
mais abrangentes, referenciados em conjunturas mais ampliadas da vida societária, chegando mesmo a atingir o nível da subjetividade, 'o sujeito', em um desses eventos.

No progressivo ampliar das parcerias estabelecidas, tanto em âmbito nacional como internacional, observa-se também uma ampliação de fronteiras que está presente no que concerne tanto ao 'Abrascão' como aos congressos específicos organizados pela associação.

É importante ainda ressaltar a diversidade de documentos produzidos nesses eventos, com destaque para as 'cartas' aprovadas em suas plenárias finais, as quais sintetizam, dentre outras questões, a posição e os encaminhamentos relativos à formulação das políticas de saúde no país (Belisário, 2002).

Aqui, procurar-se-á traçar um panorama desses importantes eventos promovidos pela Abrasco, com destaque para o Congresso Brasileiro de Saúde Coletiva - o 'Abrascão'. Far-se-á também um apanhado dos dois principais congressos por áreas específicas: os congressos de epidemiologia e os de ciências sociais. Ressalta-se que, devido aos limites deste texto, não será possível abordar todos os eventos em que a Abrasco foi co-partícipe com outras associações e/ou instituições. Quando as informações assim o permitirem, apresentar-se-á um resumo das dimensões e características de cada um dos congressos realizados pela Abrasco, desde sua fundação até os dias atuais. Para a construção e organização deste texto, utilizaram-se, como fontes preferenciais de consulta, os boletins emitidos pela associação, os anais dos eventos, seus livros de resumos, programas e demais documentos atinentes a eles.

\section{Congresso Nacional da Abrasco}

Ao iniciar sua caminhada, numa primeira incursão ainda tímida, mas ao mesmo tempo ousada para uma instituição jovem, a Abrasco, juntamente com a já instituída Associação Paulista de Saúde Pública (APSP), promove seu primeiro grande evento de dimensão nacional. Assim, o I Congresso Nacional da Abrasco é realizado simultaneamente ao II Congresso Paulista de Saúde Pública, em São Paulo, no período de 17 a 21 de abril de 1983, sob a presidência de Benedictus Philadelpho de Siqueira, numa parceria que renderia outros frutos no futuro.

Ensaiando uma já presente vocação política, o congresso apresenta como tema central de discussão a Política Nacional de Saúde, abordada com foco em quatro temas básicos: Política de Assistência Médica, Política 
de Saneamento, Política de Recursos Humanos e Participação Popular em Saúde. O significado dessa primeira iniciativa para a associação se traduziu no fato de que

o Congresso significou o lançamento da ABRASCO fora do círculo restrito dos profissionais de pós-graduação (...). Acreditamos que, após este Congresso, a ABRASCO terá o respaldo e a legitimidade necessários para ser o canal das reivindicações e lutas não só dos profissionais de Saúde Coletiva, mas também dos setores organizados da população, por melhores condições de saúde e pela democratização real da sociedade brasileira. (Siqueira, 1983:1)

Em consonância com o tema central proposto e o momento político vivenciado, alerta-se para a inexistência de um Sistema Nacional de Saúde voltado para atender às reais necessidades da população; para as conseqüências advindas das precárias condições do saneamento ambiental; para a inexistência de uma política de recursos humanos; para o fato de o complexo médico-hospitalar continuar a definir os rumos das ações de saúde a serem implantadas e para o fato de a população continuar a ser objeto das políticas de saúde e não seu sujeito.

Desde esse momento, pode-se avaliar como bastante intensa a capacidade convocatória da Abrasco. Essa avaliação está embasada no grande e surpreendente comparecimento de profissionais do setor, pois o congresso reuniu um número de participantes - cerca de dois mil - que surpreendeu os próprios organizadores. Esse fato demonstra não apenas o crescimento no número de profissionais ligados à área de $\mathrm{SC}$, já naquela época, mas também a dimensão das próximas atividades desenvolvidas pela associação.

\section{Congresso Brasileiro de Saúde Coletiva: o 'Abrascão'}

Ao perceber que era necessário ampliar seu escopo de participação e comunicação com seus associados, a Abrasco promove uma primeira reunião na Universidade do Estado do Rio de Janeiro (Uerj), no sentido de desencadear seu próprio processo de organização de congressos. Sem experiência, com pouca infra-estrutura, mas sentindo a necessidade, sobretudo política, de realizar o evento, a instituição lança-se nessa empreitada a partir de sua terceira diretoria.

Assim, o I Congresso Brasileiro de Saúde Coletiva (CBSC), ou seja, o I 'Abrascão', é realizado no período de 22 a 26 de setembro de 1986, no Rio de Janeiro, com o tema central "Reforma Sanitária e Constituinte: garantia do direito universal à saúde". 
Sob a presidência de Sebastião Loureiro, o I Congresso Brasileiro de Saúde Coletiva cumpre seu papel político em consonância com seu corpo de associados e conta com a participação de cerca de dois mil profissionais da área de SC. Sobre esse primeiro congresso, é importante destacar seu papel e a oportunidade de sua realização no momento político vivido. Um momento que vem, na seqüência e como um aprofundamento dos debates da VIII Conferência Nacional de Saúde (CNS), pouco antes da eleição para a Assembléia Nacional Constituinte.

Em discurso proferido na abertura do evento, o presidente da Abrasco caracteriza o momento político como oportuno e importante para se discutir as bases técnicas, políticas e institucionais de uma reforma sanitária que modificasse o então quadro da saúde. Ao falar sobre a VIII CNS, reforça a responsabilidade de dar continuidade ao processo e de contribuir tanto

com o conhecimento técnico e científico produzido na Saúde Coletiva, como na competência política de analisar criticamente certas conjunturas, mobilizar vontades, articular iniciativas e ações que levem adiante um projeto de transformações profundas no setor. É esta responsabilidade e este compromisso que a ABRASCO, ao organizar este congresso, quer dividir com os participantes. É este, ao nosso ver, o perfil de atuação da ABRASCO. (Loureiro, 1986:2)

Ele afirma ainda que a Abrasco procurava ser a consciência crítica do movimento progressista na saúde.

Como um "fórum científico com características marcadamente políticas" (Abrasco, 1986a:6) , a assembléia-geral e a sessão plenária final desse I Congresso aprovam declarações, propostas e moções cujo teor e amplitude refletem a abrangência das preocupações e deliberações dos mais de dois mil participantes. Aprovam ainda a organização de uma frente popular de defesa da Reforma Sanitária, tarefa a ser desenvolvida pela associação em 1987; a proposta elaborada por Eleutério Rodriguez Neto, com base no relatório da VIII CNS - a proposta de conteúdo "Saúde para a Constituição", colocada como subsídio para a discussão, com vistas à Assembléia Nacional Constituinte; e 26 moções referentes aos mais variados objetos atinentes ao setor (Abrasco, 1986a).

A declaração final desse I CBSC reveste-se de grande importância política, uma vez que, entre outras questões, reafirma

a necessidade da continuidade no processo de mobilização social em torno da reforma iniciado com a VIII CNS; o apoio à Comissão Nacional da Reforma Sanitária (...); o apoio estratégico aos avanços representados pelas AIS (...); a necessidade de construção de uma Frente Popular pela Reforma Sanitária (...); 
e o engajamento decisivo no processo constitucional, estabelecendo um projeto para a saúde a ser inscrito na nova constituição e comprometendo desde agora os candidatos com as propostas da Reforma Sanitária. (Abrasco, 1986b:1)

Para a diretoria, a realização desse congresso

representou o novo patamar na construção científica do saber, ao mesmo tempo que permitiu a formulação de propostas estratégicas da Reforma Sanitária que certamente serão inscritas na nova Constituição brasileira. (Abrasco, 1986a:6)

\section{Congresso Brasileiro de Saúde Coletiva/ III Congresso Paulista de Saúde Pública}

Num momento propício para se trabalhar um texto legal para o Sistema Único de Saúde (SUS), realiza-se o II Congresso Brasileiro de Saúde Coletiva, de 3 a 7 de julho de 1989, em São Paulo, apresentando como tema central o "Sistema Único de Saúde - conquista da sociedade". Sob a presidência de Guilherme Rodrigues da Silva e à semelhança do primeiro congresso, o evento é promovido em parceria com a Associação Paulista de Saúde Pública (APSP).

Correspondendo às expectativas, é um congresso bastante concorrido, com cerca de 2.500 participantes advindos tanto dos serviços de saúde quanto das instituições acadêmicas. Ocorre em um momento importante para a sociedade brasileira, quando irá se realizar a primeira eleição para presidente da República desde o Golpe Militar de 1964, numa conjuntura que contribui para que o congresso se transforme em espaço de definição de políticas, passíveis de serem cobradas dos futuros candidatos à presidência.

No programa do evento, além do significativo número de trabalhos e atividades realizadas, destacam-se quatro mesas-redondas, cujos temas ilustram bem o momento vivenciado: "1 - Que saúde é essa, presidente? A saúde no contexto da sucessão presidencial"; "2 - O Sistema Único de Saúde - as leis"; “3 - Sistema Único de Saúde: a operacionalização"; e "4 - Política científica e tecnológica em saúde".

A apresentação constante do programa do congresso afirma que o evento

constitui-se como um espaço de síntese e reflexão sobre o momento que a Saúde Coletiva-Saúde Pública atravessa no Brasil (...). Por outro lado revestese de fundamental importância a realização de um evento de caráter nacional, 
que possibilite o entendimento da trajetória da área da Saúde Coletiva (...) área que, apesar dos revezes [sic], caminha para sua consolidação, buscando definições metodológicas, técnicas e de conteúdo. (Abrasco, 1989b)

Em sua assembléia-geral, é aprovada a declaração final, intitulada "Carta de São Paulo", dirigida à sociedade brasileira e às comunidades científicas e de serviços da área da Saúde Coletiva (Abrasco, 1989a). Entre outras questões, a carta denuncia as condições de vida e saúde da população e as distorções do sistema de saúde, defendendo a implantação de um sistema de saúde socialmente justo e tecnicamente adequado ao Brasil contemporâneo. Denuncia ainda o que denomina "obstaculização ou desvirtuação da Reforma Sanitária", expressa no bloqueio dos canais de participação da população na definição e no controle das políticas de saúde e na desobediência à Constituição, pelo não envio no prazo estabelecido das propostas de projeto de lei sobre seguridade social, incluindo a saúde. Reafirmando os propósitos da Reforma Sanitária, a carta exige a preservação e o avanço do projeto, a aprovação imediata das leis orgânicas da seguridade social - saúde, previdência e assistência social -, a imediata instalação das instâncias colegiadas de gestão, uma reforma político-administrativa que assegure a unicidade de comando em cada esfera de poder e a garantia das bases financeiras da seguridade social. Também reafirma a retomada da política de desenvolvimento científico e tecnológico que permita a autosuficiência nacional na produção de insumos e equipamentos e o respeito ao direito constitucional de acesso do cidadão às informações de saúde de caráter individual e coletivo. Cobra, por fim, dos futuros governantes, posicionamento e compromisso em relação a essas questões.

\section{Congresso Brasileiro de SAÚde Coletiva/ I Encontro de Saúde Coletiva do Cone Sul}

Tendo como tema central "Saúde como direito à vida", ocorre em Porto Alegre (RS), de 16 a 20 de maio de 1992, sob a presidência de Arlindo Fábio Gómez de Souza, o III CBSC, em conjunto com o I Encontro de Saúde Coletiva do Cone-Sul. Observa-se que, pelo próprio caráter desse congresso, realizado no Cone-Sul, a Abrasco amplia sua perspectiva como associação em defesa dos interesses de toda a América Latina, chamando a atenção para as recentes conquistas de toda a nação brasileira, como a Constituição e a criação do SUS, entre outras.

Continuando uma tradição já iniciada, o congresso cria a oportunidade de importantes reuniões e encontros em seu interior. Nele, é introduzida a Feira de Saúde, com o objetivo de "divulgar a ciência, levando 
ao público em geral informações atuais sobre alguns temas na área da Saúde Pública/Saúde Coletiva" (Abrasco, 1992c:17). Uma iniciativa que, segundo a própria Abrasco (1992a:9), ousou "conferir ao congresso um corte popular onde a população pode compartilhar o conhecimento e a informação criada nos órgãos públicos”.

Em sua assembléia final, o IV Congresso aprova a "Carta de Porto Alegre", a qual é permeada por um sentimento de indignação em todo o seu conteúdo. Diz a carta:

indignação é o sentimento que, no momento, mais unifica os profissionais de saúde e os profissionais da Saúde Coletiva e os usuários dos serviços. Indignação com o aumento da miséria e desigualdades, na vida, na doença e na morte. Indignação face ao recrudescimento de velhas epidemias e a expansão de novas. Indignação com as chamadas políticas de ajuste econômico (...) com a privatização e o desmonte dos sistemas de saúde e de seguridade social; com a corrupção, a incompetência político-administrativa e as ameaças à ordem institucional. (Abrasco, 1992b)

Afirma também a necessidade do fortalecimento das instituições democráticas; da adoção de políticas econômicas de educação, saúde, seguridade social, ciência e tecnologia, condizentes com o desenvolvimento desses países; da redução das desigualdades sociais e regionais e da promoção do bem de todos, sem preconceitos e discriminações, de modo que prevaleçam os direitos humanos e a defesa da paz. Enfatiza as conquistas relativas à promulgação da Constituinte, ao mesmo tempo que alerta para os riscos de perdê-las, e aponta a IX Conferência, que ainda seria realizada, como uma oportunidade de reafirmação, por parte da sociedade, de seu projeto de Reforma Sanitária e de estabelecimento de diretrizes para a política nacional de saúde dos próximos anos (Abrasco, 1992b). Por último, acentua:

diante deste quadro de indignação, o movimento pela redemocratização da saúde rearticula suas forças e investe na criatividade - este III Congresso e I Encontro representam o fortalecimento deste movimento, pois ampliaram o diálogo entre irmãos do Cone-Sul em termos de experiências e de desenvolvimento científico e tecnológico além de promover a aproximação da produção acadêmica aos serviços de saúde. (Abrasco, 1992b)

\section{Congresso Brasileiro de Saúde Coletiva}

Com o tema "Saúde, o feito por fazer", realiza-se em Olinda (PE), de 19 a 23 de junho de 1994, o IV CBSC, também sob a presidência de Arlindo Fábio Gómez de Souza. Numa demonstração indiscutível de seu poder convocatório, a Abrasco reúne cerca de 3.800 participantes nesse 
evento que conta, em sua programação, com um grande contingente de trabalhos científicos e diversas atividades. Esse é um congresso que introduz novidades em sua organização/programação, a qual se desenvolve com base em eixos temáticos, realiza-se fora do eixo Rio-São Paulo (um compromisso da diretoria) e possibilita encontros setoriais em seu interior.

Em relação ao último ponto, propicia a realização de eventos especiais, como a I Reunião Nacional de Conselheiros de Saúde, o Encontro Nacional de Representantes de Comissões de Saúde do Legislativo, a reunião conjunta do Conselho Nacional de Secretários de Saúde (Conass) e do Conselho Nacional de Secretários Municipais de Saúde (Conasems), a reunião das organizações não-governamentais (ONGs) ligadas à saúde, bem como a assembléia do Centro Brasileiro de Estudos de Saúde (Cebes). À semelhança do III CBSC, esse também promove a Feira de Saúde - um espaço de integração entre os congressistas e a população local.

O IV Congresso acontece num ano importante, de construção da democracia no Brasil, momento de renovação de mandatos tanto no Executivo como no Legislativo. Na apresentação de seu programa, é explicada a escolha do tema "Saúde, o feito por fazer". Para a Abrasco,

O tema é rico em simbologias: refere-se à gravidade da situação sanitária e social da população brasileira, ao percurso difícil e tortuoso do setor saúde nos últimos anos e, finalmente, ao compromisso, que todos devem reafirmar, de continuar nossa luta pelo direito à saúde. (Abrasco, 1994b)

Sua dimensão o aponta como detentor de

uma dimensão política especial e deve constituir num [sic] espaço privilegiado para a ampliação e o aprofundamento do debate do 'feito por fazer'. Pretende, ainda, contribuir para a avaliação e a atualização do projeto de construção da Saúde Coletiva no Brasil, através da interação de esforços de representantes da academia e dos serviços. (Abrasco, 1994b)

Em sua assembléia-geral é aprovada a Carta de Pernambuco, encaminhada aos então candidatos à Presidência da República (Abrasco, 1994a). A carta, uma síntese das discussões travadas durante o congresso, apresenta um diagnóstico da saúde no Brasil, apontando a degradação do sistema, o reaparecimento de doenças consideradas extintas como o cólera e a dengue, o aumento da violência e a persistência de problemas como a fome e a miséria como parte do perfil da saúde no país.

A falta de recursos para o setor e o sucateamento também são ressaltados. A carta aponta seu alvo:

Destina-se esta carta, primordialmente, a resgatar a esperança num futuro mais digno e a credibilidade nos serviços públicos de saúde do País (...); 
destina-se a seus organismos representativos - associações da sociedade civil, notadamente Organizações Não Governamentais [sic] e movimentos populares; destina-se aos poderes constituídos em todos os níveis e esferas; destina-se enfim aos partidos políticos; e aos candidatos comprometidos com a democracia e a emancipação social do povo brasileiro (...). (Abrasco, 1994a)

A avaliação do IV CBSC é positiva, destacando-se, entre outras questões, a integração de novos atores políticos, a integração academia/ serviços e a amplitude do temário discutido, pois o congresso encaminhou proposições que foram desde a manutenção do texto constitucional, no que se refere à seguridade social, até novos modelos de atenção já experimentados com êxito pelo país. A diretoria assinalou:

saímos do congresso fortalecidos na idéia da necessidade de um trabalho que responda ao conceito de saúde que colocamos na constituição, que rompa com a setorialização das ações, que amplie a democratização do Estado brasileiro, que contribua efetivamente para a melhoria das condições da saúde e de vida de nosso povo. (Abrasco, 1994c:3)

\section{Congresso Brasileiro de Saúde Coletiva/ V Congresso Paulista de Saúde Pública}

Sob a presidência de Rita de Cássia Barradas Barata e em mais uma promoção conjunta com a Associação Paulista de Saúde Pública (APSP), a Abrasco realiza de 25 a 29 de agosto de 1997, em Águas de Lindóia (SP), o V CBSC, com o tema "Saúde, responsabilidade do Estado contemporâneo". O contexto de sua realização é apresentado como um

momento histórico em que o cenário internacional se apresenta para atingir um modelo de proteção social fundado na solidariedade redistributivista e na consagração de um patamar de acesso a um conjunto de bens identificados com os padrões de cidadania conquistados no mundo desenvolvido. (Abrasco, 1997b)

Em número especial dedicado ao evento, a revista Tema, do Projeto Reunião, Análise e Difusão de Informações sobre Saúde (Radis), ressalta que

não é exagero afirmar que foram poucos os momentos em que a história deste País teve a oportunidade de reunir um número tão expressivo de autoridades, gestores, profissionais, pesquisadores e usuários do sistema de saúde, com o objetivo de propor alternativas para o setor. (Nascimento, 1997:2) 
$\mathrm{Na}$ apresentação do livro de resumos, os promotores do evento afirmam que

mais uma vez, pretendemos que os nossos congressos, para além de eventos científicos de exposição e discussão da nossa produção, possam ser o local onde se encontrem os acadêmicos, com suas questões, os profissionais de saúde, com suas problemáticas, e segmentos da população, com suas necessidades. (Abrasco, 1997c)

Mantendo o seu poder de convocação, a associação conta, nesse evento, com cerca de 2.500 participantes e proporciona mais de trinta reuniões, encontros e assembléias. Tendo como fio condutor dos debates a análise da responsabilidade do Estado contemporâneo para com a saúde, o tema central é desdobrado "em suas múltiplas facetas, considerando a participação dos diferentes interesses e subáreas temáticas do campo da Saúde Coletiva" (Abrasco, 1997a).

Em seu discurso de abertura, a presidente da Abrasco justifica o porquê da necessidade e da contemporaneidade do retorno ao tema escolhido para o congresso, destacando entre outras questões que

a conjuntura internacional dos anos 90 trouxe a vaga neoliberal e a revisão do papel do Estado, apontando os avanços das conquistas sociais como resquícios arcaicos do período das revoluções sociais que haviam marcado a primeira metade deste século. (Barata, 1997)

Ela afirma que, apesar do avanço no sentido da construção de um modelo democrático de atuação, os princípios que estiveram e continuam na base da formulação do direito à saúde, fundamentos do SUS, "estão sendo ameaçados nesse embate entre as condições individualistas e liberais e as concepções coletivas e solidárias" (Barata, 1997). E acrescenta mais um princípio aos anteriormente consagrados: o de compromisso com a qualidade, "nosso maior desafio na direção da construção da cidadania" (Barata, 1997).

\section{Congresso Brasileiro de Saúde Coletiva}

O último 'Abrascão' do século é realizado no ano em que a associação completa vinte anos de fundação. Assim, sob a presidência de Rita Barata, a Abrasco realiza seu VI CBSC no período de 28 de agosto a 1o de setembro de 2000, em Salvador (BA), e traz como tema central de discussão "O sujeito na Saúde Coletiva".

Para os organizadores do evento, a discussão do sujeito é assim apresentada: "queremos discutir o Sujeito em suas múltiplas dimensões, 
buscando aprofundar nossa compreensão acerca das relações dialéticas entre o indivíduo e a coletividade" (Abrasco, 2000b).

Ainda para os organizadores,

este congresso, mais que o fato de congregar os profissionais de saúde, significa uma oportunidade ímpar para uma reflexão ampla e aprofundada sobre as condições e os determinantes da situação de saúde no Brasil, neste limiar de milênio. (Abrasco, 2000c:1)

O tema "O sujeito na Saúde Coletiva" e a utilização de novas regras em sua organização fazem com que esse evento fuja um pouco do formato tradicional dos congressos anteriores, demonstrando uma mudança de perspectiva em relação a ele. Uma mudança advinda, entre outros fatores, da necessidade de a Abrasco refletir, após vinte anos de atividades como associação científica da área, "sobre quem é o sujeito na e da Saúde Coletiva" (Abrasco, 2000b). Para Paim (2000:3),

Devemos recuperar a idéia de sujeito sem negar a idéia de estrutura, resgatando o papel do sujeito histórico na conservação ou na mudança dessas estruturas. Temos que considerar ainda que esse sujeito da saúde coletiva, capaz de processar tais mudanças, pode ser, além do sujeito individual, uma personalidade, uma liderança. Podemos falar em sujeito social, que pode ser definido como uma entidade, a exemplo da própria ABRASCO, ou de um partido político, um sindicato, uma associação de bairro, etc...

A organização do congresso realiza quatro grandes conferências, que apresentam sujeitos de diferentes formas: o sujeito ético, o histórico, o social e o saudável. Apresenta, também, grandes debates que abordam a transversalidade, a transdisciplinaridade, a transetorialidade, a transformação, a transição e a transculturalidade,

privilegiando os diferentes deslocamentos a que o Sujeito está submetido, ou produz, no processo de construção de sua vida enquanto ser genérico, permitindo o trânsito para outros campos de conhecimento nos quais a Saúde Coletiva pode e deve buscar elementos para sua própria construção. (Abrasco, 2000b)

São utilizadas novas regras em sua organização - inovações relativas aos critérios de seleção dos trabalhos, à inclusão de pesquisadores em início de carreira, à inclusão de um maior número de conferencistas e palestrantes, à prioridade dada à qualidade, à diversidade e à variedade de conteúdos e à maior participação, na programação, de relatos de experiências de serviços. Sendo assim, "investigações originais, ensaios teóricoconceituais e relatos relevantes sobre a descentralização e reorganização dos serviços públicos de saúde do país" (Abrasco, 2000a:4) constituíram o 
perfil dos trabalhos apresentados durante o VI CBSC. A Feira da Saúde, evento inaugurado no III Congresso realizado no Rio Grande do Sul e novamente realizado no IV CBSC, em Olinda (PE), também acontece em Salvador.

O VI Congresso tem uma participação recorde, cerca de cinco mil pessoas. Um crescimento resultante, provavelmente, de três movimentos principais:

o aumento dos cursos de pós-graduação stricto e lato sensu; a existência de um maior número de profissionais de saúde desejosos de compartilhar suas experiências de trabalho; a consolidação e o prestígio da Abrasco como organização capaz de articular tanto a produção acadêmica quanto o conhecimento que é desenvolvido nos serviços de saúde. (Barata, 2000: 5)

\section{Congresso Brasileiro de Saúde Coletiva}

O primeiro 'Abrascão' do século XXI realiza-se no período de 29 de julho a 2 de agosto de 2003, em Brasília. A discussão acerca da necessidade de se enfrentar a desigualdade existente e persistente no país inspira a escolha do tema central deste VII Congresso, "Saúde, justiça, cidadania", assim justificada:

A secular desigualdade que caracteriza o Brasil e a determinação social dos processos saúde/doença levou a Abrasco a eleger como tema central de seu congresso "Saúde, justiça, cidadania". No evento será debatida a superação das desigualdades sociais, o acesso e a utilização desigual dos serviços de saúde e a obtenção de atenção integral e resolutiva, parte da agenda de estados democráticos. (Abrasco, 2002b:9)

É um tema que dialoga com diversos campos disciplinares, como o direito, a educação, a comunicação social e as ciências humanas, dentre outros.

Realiza-se o evento em um importante momento da vida nacional, correspondente ao início de novas legislaturas em âmbito federal e estadual, tendo sido avaliado como o congresso da diversidade, da inclusão e da criatividade.

O número recorde de trabalhos, cerca de 6.400 , evidencia para a comissão científica "a consolidação do campo da Saúde Coletiva no país e a Abrasco como entidade de grande poder convocatório e associativo" (Abrasco, 2003b:7). Um salto em relação ao congresso anterior, o que mais uma vez reforça não só o poder convocatório da associação como também seu papel como entidade acadêmica e política de referência nacional na área da saúde. Destaque-se também o grande comparecimento 
dos profissionais inseridos nos serviços de saúde, os quais contribuíram com grande contingente de trabalhos.

Concomitantemente ao desenvolvimento das atividades do congresso, houve a apresentação de um conjunto de atividades culturais denominado "Cultura é saúde", enfocando o tema saúde. Essas atividades estiveram presentes durante todo o congresso e compreenderam diferentes manifestações que promoveram uma interação entre a arte e a saúde. Também no evento ocorreu a IV Mostra Nacional de Vídeos em Saúde - a IV Vídeo Saúde, organizada pelo Centro de Informação Científica e Tecnológica do Departamento de Comunicação e Saúde da Fundação Oswaldo Cruz.

Para a Abrasco, o

VII CBSC foi o maior evento da fase preparatória da XII Conferência Nacional de Saúde-Conferência Sérgio Arouca. Por certo, os ecos do nosso congresso estão ressoando na sua etapa de debates municipais e estarão também nas conferências estaduais e nacional, alimentando os debates com a profusão, profundidade e diversidade dos temas abordados nas distintas atividades que ocorreram em Brasília. (Abrasco, 2003a:3)

\section{Congresso Brasileiro de Saúde Coletiva/ XI Congresso Mundial de Saúde Pública}

Realizado no período de 21 a 25 de agosto de 2006, no Rio de Janeiro, o VIII Congresso Brasileiro de Saúde Coletiva e o XI Congresso Mundial de Saúde Pública apresentam como tema central "Saúde Coletiva em um mundo globalizado: rompendo barreiras sociais, econômicas e políticas". Esse evento representa um salto da Abrasco, que se lança numa jornada internacional ao promovê-lo juntamente com a Federação Mundial das Associações de Saúde Pública (World Federation of Public Health Associations-WFPHA). É um salto que, na verdade, já vinha se insinuando e sendo construído há algum tempo e que encontra sua materialização na realização desse congresso.

O ex-presidente da Abrasco José Carvalho de Noronha ilustra bem a entrada da associação no cenário internacional dizendo que ela "nunca esteve fora", uma vez que, ao ser fundada no final dos anos 70, o foi "sob a égide largamente aceita de uma reforma democrática internacional da utopia de um mundo de irmãos", acentuando que "havia uma visão internacionalista". Sendo assim, afirma ainda que, "em relação às políticas de saúde, a ABRASCO já nasce universalista e imbuída da idéia de solidariedade latino-americana" (Noronha, 2005:6). 
Essa vocação está presente ao longo da trajetória da entidade, que manteve atuações com parceiros tanto nacionais como internacionais, com destaque para a Associação Latino-Americana e do Caribe de Educação em Saúde Pública (Alaesp), a Associação Latino-Americana de Medicina Social (Alames) e a Organização Pan-Americana da Saúde (Opas). O alcance e as dimensões dessa nova empreitada da Abrasco fogem do alcance deste artigo; contudo, não é difícil inferir que a instituição inaugurará uma nova era, impondo uma nova dinâmica ao já consagrado 'Abrascão'.

\section{Os Congressos por Áreas Específicas:}

\section{A EPIDEMIOLOGIA}

\section{Congresso Brasileiro de Epidemiologia}

Primeiro congresso por área específica de conhecimento realizado pela Abrasco, o I Congresso Brasileiro de Epidemiologia acontece em Campinas (SP), no período de 2 a 6 de setembro de 1990, sob a presidência de José da Silva Guedes e contando com Marilisa Berti Barros como presidente do evento. Tendo como tema central "Epidemiologia e desigualdade social: os desafios do final do século" e o objetivo de contribuir para a formação de recursos humanos especializados, esse primeiro congresso surpreende por seu poder convocatório e mobilizador, contando com cerca de 1.500 participantes.

Do total de inscritos, 25 procediam de outros países, 954 vieram da Região Sudeste, 175 da Região Nordeste, 157 da Região Sul, 63 da Região Centro-Oeste e trinta da Região Norte (Abrasco, 1990). No que se refere à procedência institucional dos participantes, $48 \%$ eram da universidade, $44 \%$ dos serviços de saúde e $8 \%$ de instituições de pesquisa não vinculadas às universidades (Abrasco, 1990).

Sua realização representa o resultado do trabalho desenvolvido pela Comissão de Epidemiologia da Abrasco, uma das primeiras a se estruturar dentro da associação, juntamente com docentes do Departamento de Medicina Preventiva e Social da Universidade Estadual de Campinas (Unicamp), e se dá como desdobramento de uma série de iniciativas que incluem seminários, reuniões, cursos e publicações, sistematizadas na elaboração do Plano Diretor para a Epidemiologia no Brasil. Nesse contexto, o congresso figura como uma das propostas para o estímulo à produção de pesquisas e à divulgação de seus resultados. 
Em seu discurso na abertura do evento, o presidente da Abrasco avalia suas dimensões, consideradas surpreendentes, mas afirma ser tal fenômeno compreensível, ao rememorar os 11 anos da associação (Guedes, 1990).

\section{Congresso Brasileiro de Epidemiologia}

Seguindo seu percurso e confirmando a periodicidade dos congressos de epidemiologia, realiza-se em Belo Horizonte (MG), de 13 a 17 de julho de 1992, o II Congresso Brasileiro de Epidemiologia, sob a presidência de Arlindo Fábio Gómez de Souza e tendo Maria Fernanda Furtado de Lima e Costa como presidente do evento. O tema "Qualidade de vida: compromisso histórico da epidemiologia" é escolhido como o norteador das discussões, enfatizando as questões político-sociais que perpassam a área.

Para seus organizadores, o II Congresso consolidou os avanços do primeiro e aperfeiçoou alguns aspectos, no sentido de torná-lo mais produtivo. $\mathrm{Na}$ apresentação do livro com o programa e os resumos, afirmam que

a realização deste evento representa a consolidação da periodicidade dos congressos de epidemiologia e espera-se que o esforço conjunto dos participantes contribua para o desenvolvimento da epidemiologia e reafirme seu compromisso com a qualidade de vida da população brasileira. (Abrasco, 1992d:5)

Contando com a participação de cerca de 1.100 inscritos e uma grande quantidade de trabalhos científicos, confirma e reforça a capacidade de mobilização crescente. A quantidade e a qualidade dos trabalhos apresentados são vistas como uma confirmação da relevância do evento para o crescimento e a consolidação da disciplina no país. A troca de experiências entre profissionais de diversas origens institucionais e com diferentes perfis de formação também contribuiu para essa consolidação.

\section{Congresso Brasileiro de EPIDEMIOlogia (Epid 95)/ \\ II Congresso Ibero-Americano de Epidemiologia/ \\ I Congresso Latino-Americano de Epidemiologia/ \\ I Mostra de TeCnOlogia em Epidemiologia}

Numa demonstração de consolidação e difusão da área, a epidemiologia realiza de 24 a 28 de abril de 1995, em Salvador (BA), um evento de proporções internacionais: o III Congresso Brasileiro de Epidemiologia/II Congresso Ibero-Americano de Epidemiologia/ I Congresso Latino-Americano de Epidemiologia/I Mostra de Tecnologia 
em Epidemiologia. É uma promoção conjunta da Sociedade IberoAmericana de Epidemiologia (Siae) e da Associação Latino-Americana de Medicina Social (Alames) com a Associação Brasileira de Pós-Graduação em Saúde Coletiva. Na época, Maria Cecília de Souza Minayo ocupava a presidência da Abrasco.

Com o tema "A epidemiologia na busca da eqüidade em saúde", esse congresso apresenta um recorde de cerca de 3.500 participantes de 22 países. Os organizadores ressaltam o volume de trabalhos representado pelas

1.501 comunicações científicas através de posters distribuídos em 24 seções, ou através de 89 comunicações coordenadas representando as tendências mais recentes da nossa produção. (Abrasco, 1995d:1)

Atribui-se tal participação aos avanços registrados pela epidemiologia e ao crescente número de grupos e pesquisadores qualificados e atuantes na área.

À semelhança dos anteriores, o evento se realiza em consonância com as bases e diretrizes definidas no Plano Diretor para o Desenvolvimento da Epidemiologia no Brasil, do qual a Abrasco apresentou uma versão atualizada, consubstanciada no II Plano 1995-1999.

Em boletim especialmente dirigido ao congresso, a Comissão de Epidemiologia afirma, em editorial:

a institucionalização desses eventos constitui mais um passo substancial dentro do processo de resgate da epidemiologia, que vem sendo construído pela ABRASCO ao longo dos últimos 12 anos, com vistas à sua legitimação. (Abrasco, 1995a)

A I Mostra de Tecnologia em Epidemiologia (Epitec) é apontada como uma iniciativa pioneira, marco inicial de um novo processo na área de Saúde Coletiva e de demonstração da relevância social de sua produção tecnológica.

São promovidos, por diversos grupos e entidades, vários eventos paralelos, dentre eles o I Congresso Nacional dos Conselhos de Saúde SUS-Brasil, organizado a partir dos conselhos estaduais e municipais de Saúde com o propósito de articular a organização, a atuação e a formação de conselheiros. Sua plenária final aprova um documento em defesa do Sistema Único de Saúde (SUS) e contra a revisão constitucional na saúde.

No discurso de abertura, proferido pelo presidente do congresso, Maurício Barreto, são recapituladas a organização do movimento da epidemiologia no Brasil, a criação da Comissão de Epidemiologia da Abrasco, a elaboração do Plano Diretor para o desenvolvimento da área e a realização dos dois congressos. Para Barreto (1995:2-3), a escolha do tema reafirma 
a nossa crença de que, ao produzir conhecimento científico, por mais simples e fundamental que seja, se deve ter o compromisso de modificação da realidade que nos cerca. (...) a epidemio latino-americana nasce da busca militante por mudanças urgentes da realidade e, como tal, procura se definir como uma disciplina científica, com tudo o que isto significa, incluindo o compromisso de fundamentar as transformações que se impõem às nossas sociedades.

A plenária final do congresso aprova a "Carta de Salvador", na qual são apresentadas reflexões sobre o processo de globalização, as conquistas tecnológicas e suas repercussões para a vida e a saúde das pessoas. A carta convoca os participantes do congresso a assumirem

o compromisso de intensificar o trabalho na busca da equidade, na defesa da vida com dignidade e na consolidação dos avanços já alcançados, além de enfrentar os desafios hoje conhecidos e aqueles surgidos diariamente no esforço por entender e transformar a situação de vida e saúde dos povos dos quais somos e nos sentimos parte. (Abrasco, 1995b:5)

\section{Congresso Brasileiro de Epidemiologia (Epirio-98)}

Último congresso específico a se realizar no século $\mathrm{XX}$, o IV Congresso Brasileiro de Epidemiologia revestiu-se de caráter especial ao apontar as contribuições históricas da epidemiologia para o bem-estar das populações, bem como os desafios ainda existentes e aqueles já delineados no novo século.

Tendo como horizonte esses desafios, é escolhido o tema "Epidemiologia em perspectiva: novos tempos, pessoas e lugares". Classificado por seu presidente, Sérgio Koifman, como um dos principais eventos na área da Saúde Coletiva no Brasil, acontece no período de 1o a 5 de agosto de 1998, no Rio de Janeiro, sob a presidência de Rita de Cássia Barradas Barata. Mais uma vez, um evento dessa natureza apresenta proporções surpreendentes, com cerca de 2.200 participantes e 1.550 trabalhos. No programa é ressaltada a magnitude do evento, composto por 94 sessões de comunicações coordenadas, 57 painéis e cerca de 1.200 pôsteres (Abrasco, 1998b).

Devido a sua importância e magnitude, é objeto de um número especial da revista Tema do Projeto Radis, que apresenta um painel sobre os principais temas tratados no congresso.

Em boletim especial para o congresso, o editorial aborda o crescimento e a maturidade da epidemiologia no campo da Saúde Coletiva brasileira e afirma que a escolha do tema pretendeu 
sintetizar nosso olhar para o futuro embasado nos acúmulos obtidos no passado e o trabalho do presente. Além da perspectiva histórica, esse lema continha em si a proposta de resgate da Epidemiologia Descritiva como ferramenta de compreensão da realidade (...). (Abrasco, 1998a:1)

Em seu discurso de abertura, Koifman aponta ser esse o momento de analisarmos criticamente nossas heranças e legado histórico nos campos da Epidemiologia e suas interrelações [sic] com a Saúde Pública e a Medicina Social. Trata-se de um momento especial voltado para a avaliação de nossa real compreensão das peculiaridades das condições de saúde de nosso povo, e de nossa capacidade e compromisso em contribuir para sua transformação. (Koifman, 1998:2)

\section{Congresso Brasileiro de Epidemiologia (Epi-2002)}

\section{Tendo como objetivos}

instigar a vocação de novos pesquisadores e aglutinar todas as possibilidades e campos de pesquisa da epidemiologia por meio do encontro das novas concepções da Promoção à Saúde que responde a vários problemas, como os desafios trazidos pela persistência das novas velhas doenças, a emergência de novas patologias, os agravamentos dos problemas de saúde decorrentes dos modernos estilos de vida, com a epidemiologia que oferece instrumentos para a compreensão e aprimoramento dos preceitos desta Promoção (Abrasco, 2001),

realiza-se de 23 a 27 de março de 2002, em Curitiba (PR), o V Congresso Brasileiro de Epidemiologia, com Moisés Goldbaum na presidência do evento e José Carvalho de Noronha na presidência da Abrasco.

Sua realização no Paraná partiu de uma demanda da Secretaria de Estado da Saúde e foi incorporada e assumida pelas instituições acadêmicas, o que

re-introduz [sic] uma das características da Epidemiologia: a sua incorporação nos serviços de saúde, imprimindo, assim, fortes estímulos para o processo e regionalização e descentralização da pesquisa científica. (Goldbaum, 2001:8)

Com o tema "A epidemiologia na promoção da saúde", esse foi o primeiro congresso do novo século e contou com ampla participação dos pesquisadores e estudiosos da área, expressa no envio de mais de 2.800 resumos, número superior ao dos congressos anteriores. Contou também com convidados internacionais de 11 países.

Para Goldbaum (2001:8), presidente do congresso,

a epidemiologia oferece poderosos instrumentos para a compreensão e aprimoramento dos preceitos da Promoção à Saúde. No encontro destes dois campos, a Comissão Organizadora identificou o tema central deste evento - 
A Epidemiologia na Promoção da Saúde - consciente de que este tema aglutinará, como em momentos anteriores, todas as possibilidades e campos de pesquisa da Epidemiologia, bem como instigará as vocações de nossos pesquisadores.

Para a Abrasco, o EPI-2002 foi um evento no qual as grandes questões da epidemiologia contemporânea puderam ser abordadas e aprofundadas, contemplando-se também

todo o espectro da nosologia moderna, incluindo as doenças infecciosas, em especial aAids, as doenças crônicas, com destaque, entre outros, para os problemas do envelhecimento. Na perspectiva teórica, foram revistas em profundidade as questões conceituais e abordados os aspectos de modelagem, pasșando pelas modernas técnicas de tratamento espacial de dados. (Abrasco, 2002a:8)

Temas como saúde ambiental, saúde bucal e violência também encontraram espaço para serem debatidos. Algumas sessões especiais foram realizadas, para se debater a epidemia de dengue e a criação da Agência Federal de Controle de Doenças. Segundo a Abrasco,

todo o debate gerado durante o Epi2002, enriquecido pela presença de convidados nacionais e internacionais de instituições acadêmicas prestigiadas, e de serviços de saúde, cumpriu dupla missão. Por um lado fortaleceu e deixou evidente a maturidade teórica e metodológica da Epidemiologia brasileira, além de sinalizar caminhos e perspectivas para o seu contínuo progresso e aprimoramento. (Abrasco, 2002a:9)

O EPI-2002 aconteceu no mesmo ano em que a Organização PanAmericana da Saúde (Opas) completava o seu centenário, o que permitiu a realização de uma sessão comemorativa do evento, ressaltando o trabalho da organização no desenvolvimento da Saúde Pública nas Américas.

\section{Congresso Brasileiro de EpidEMIologia}

"Um olhar sobre a cidade" foi o tema escolhido para o VI Congresso Brasileiro de Epidemiologia, realizado em Recife (PE) de 19 a 23 de junho de 2004, sob a presidência de Moisés Goldbaum. Para a Associação Brasileira de Pós-Graduação em Saúde Coletiva, a pretensão era "enfocar a cidade na perspectiva epidemiológica, contemplando sua natureza multi e transdisciplinar" (Abrasco, 2004a:6).

Com uma participação ainda mais surpreendente, esse congresso contou com cerca de quatro mil pesquisadores provenientes das instituições acadêmicas e dos serviços de saúde e mais de 3.800 trabalhos inscritos e avaliados. Abrangendo ampla temática, o congresso discutiu 
desde o desenvolvimento teórico conceitual e de modelos matemáticos, passando pela análise de questões específicas (com destaque para a violência, envelhecimento e saúde ambiental) ou de questões gerais (como eqüidade), criou uma vez mais a oportunidade para aprimorar o intercâmbio entre os pesquisadores e estimular o aprofundamento das interações entre os setores acadêmicos e de serviços. (Abrasco, 2004b:2)

Dentre suas propostas finais, destaca-se o acordo para $o$ estabelecimento de uma Rede Latino-Americana e do Caribe de Epidemiologia (Epilac), fruto de uma oficina de trabalho que versou sobre o desenvolvimento da epidemiologia na América Latina.

Para a presidente do congresso, Ana Bernarda Ludermir, "os epidemiologistas incidiram seu olhar sobre um cenário singular - a cidade para perscrutar desigualdades e iniqüidades no processo de adoecimento e morte" (Ludermir, 2004). Em seu entender, "a cidade cartografada assinala o lugar dos incluídos e dos excluídos do desenvolvimento". Ela espera que "esses olhares também deixem marcas como nos eventos anteriores: novas pontes, novas revelações, novas tecnologias" (Ludermir, 2004).

\section{Os Congressos por Áreas Específicas:} AS CIÊNCIAS SOCIAIS

\section{Encontro Brasileiro de CiênCias Sociais em Saúde}

As ciências sociais constituem outra área organizada da Saúde Coletiva que se faz representar em fóruns específicos, numa participação mais orgânica no campo. Essa área, que teve importante participação na constituição do campo da Saúde Coletiva, promove não um congresso, nesse primeiro momento, mas um encontro, como sua primeira reunião mais sistematizada e ampliada de profissionais praticantes e interessados na disciplina ciências sociais em saúde. Trata-se do I Encontro Brasileiro de Ciências Sociais em Saúde. Assim, com grande expectativa, essa primeira reunião é realizada em Belo Horizonte $(\mathrm{MG})$, de 28 de setembro a $1^{\circ}$ de outubro de 1993, contando com a presença de 220 participantes.

A publicação de parte de sua produção científica em forma de anais teve como objetivo "registrar a primeira reunião mais ampliada e sistematizada de profissionais praticantes e interessados nessa disciplina" (Abrasco, 1993).

Em conferência proferida na abertura do evento, o então presidente da Abrasco, Arlindo Fábio Gómez de Souza, expressa a preocupação com o desenvolvimento da área, afirmando: 
do ponto de vista da ABRASCO, temos expectativa da reconstituição de uma comissão permanente de ciências sociais, nos moldes da de epidemiologia, e daquela que pretendemos organizar na área de planejamento. (Souza, 1993:23-24)

O importante papel desempenhado pelos cientistas sociais na área de saúde e na constituição do campo da Saúde Coletiva é ressaltado no programa do encontro.

\section{Congresso Brasileiro de Ciências Sociais em Saúde}

Em continuidade às reflexões iniciadas no I Encontro, realiza-se em Curitiba (PR), de 7 a 10 de novembro de 1995, estando a Abrasco sob a presidência de Maria Cecília de Souza Minayo, o I Congresso Brasileiro de Ciências Sociais em Saúde, com o tema central "Cidade e saúde".

Promover o intercâmbio entre as diferentes instituições e marcar a presença das ciências sociais no campo da saúde, de forma mais amadurecida e com maior identidade própria, na reflexão e na análise dos processos e das várias dimensões implicadas na questão da saúde, apresentam-se como objetivos desse evento.

Para Ana Maria Canesqui, presidente do congresso,

Cidade e Saúde, tema do congresso, enseja várias reflexões, não só quanto à polifonia do espaço urbano e à concentração da desigualdade social projetada na morbimortalidade, como também [quanto] às possibilidades múltiplas de intervenções intersetoriais e específicas de saúde pelo poder público, reorganizando o espaço urbano e oferecendo melhor qualidade de vida à população. (Canesqui, 1995:2-3)

Numa demonstração de amadurecimento e legitimidade da área, o congresso conta com cerca de quinhentos participantes provenientes tanto de universidades como dos serviços de saúde, secretarias estaduais e municipais de Saúde.

No discurso de abertura do evento, Ana Maria Canesqui reconhece o quanto as ciências sociais têm contribuído tanto no âmbito da Saúde Coletiva, no processo de constituição do campo no Brasil, como no âmbito de outras áreas médicas, adquirindo certo grau de legitimidade no campo da saúde. Ela reforça a necessidade de amadurecimento das bases da profissionalização das ciências sociais no campo da saúde, da consolidação de sua identidade própria, de abertura de espaço para outros papéis e outras questões e da ultrapassagem da produção do saber militante, bem como da criação de novos espaços, no sentido de apoiar a consolidação do SUS. 
Na plenária final é aprovada a "Carta de Curitiba", a qual afirma que o tema do congresso "enseja novas reflexões sobre a modernidade e sua possível superação, bem como a necessidade de se garantir qualidade de vida para as populações" (Abrasco, 1995c:1).

Em seu texto, a carta adota a concepção ampliada de saúde definida na VIII Conferência Nacional de Saúde e reconhece, entre outras questões, que as políticas de saúde devem ser formuladas e implementadas de forma integrada a um conjunto de políticas sociais, obedecendo a critérios de qualidade, respeitando a cidadania, o caráter público das ações e serviços de saúde. $\mathrm{O}$ documento observa o quanto a perda progressiva do espaço público, que acompanha o atual processo de metropolização, acarreta danos físicos, sociais e morais às populações e ao ambiente (Abrasco, 1995c). Avalia como socialmente importante e teoricamente relevante a integração entre as instituições de ensino e pesquisa, os serviços de saúde e a vida das populações, valorizando os indivíduos, os grupos e as coletividades. Demonstra ainda a profícua interação que pode e deve haver entre cientistas sociais e destes com os profissionais que integram o campo da Saúde Coletiva (Abrasco, 1995c).

\section{Congresso Brasileiro de CiênCias Sociais em Saúde}

Como demonstrado, observa-se o crescimento e a legitimação crescentes da área de ciências sociais no interior da associação. À semelhança do ocorrido com os congressos de epidemiologia, esse também se constituiu como um processo decorrente de fóruns e oficinas de trabalho, em um momento de explicitação de uma outra área, a qual também elaborou e reelaborou o seu plano diretor.

Após a realização de seu primeiro congresso, a área promove no período de 7 a 10 de dezembro de 1999, em São Paulo, sob a presidência de Rita Barata na Abrasco e tendo Paulete Goldenberg como presidente do evento, o II Congresso Brasileiro de Ciências Sociais em Saúde, de proporções ainda maiores que o anterior. Com o tema central "Ciências sociais e saúde: objetos, tendências e abordagens”, a apresentação do Livro de Resumos desse II Congresso ressalta que o evento

está norteado pela identificação de tendências, objetos e abordagens nesta área de produção científica do campo da Saúde Coletiva, no quadro de significativas mudanças sócio-políticas $[$ sic] que atravessam a sociedade brasileira. (Abrasco, 1999)

Afirma ainda que "seu formato procurou contemplar a conexão entre esses dois campos de atividade intelectual, bem como a maior ou menor aproximação com as práticas nele inspiradas" (Abrasco, 1999). 
O elevado número de trabalhos inscritos surpreende e o temário é constituído por 24 itens, numa demonstração da variedade e das possibilidades de abordagens e aprofundamentos.

O relatório final do congresso classifica-o, comparativamente aos demais eventos da área de Saúde Coletiva, como um evento de porte médio, devido à presença de 578 congressistas.

No que se refere à procedência dos participantes, o relatório final aponta a presença de congressistas provenientes de todos os estados brasileiros, com uma predominância da Região Sudeste $(69,05 \%)$, em sua maioria do Estado de São Paulo (Abrasco, 2000e). Essa participação é seguida pela Região Nordeste, com 16,90\% dos congressistas; da Região Sul, com 8,45\%; da Centro-Oeste, com 4,75\%; e, por fim, da Região Norte, com 0,85\% dos congressistas (Abrasco, 2000d).

Quanto à procedência institucional, esta se concentrou majoritariamente naqueles participantes provenientes de instituições de ensino e pesquisa públicas, tanto federais quanto estaduais $(87,53 \%)$. Os serviços de saúde foram representados por um contingente de $8,3 \%$ dos congressistas, também em sua maioria provenientes de instituições públicas $(73,18 \%)$. Não foram identificadas cerca de $4 \%$ das instituições de origem (Abrasco, 2000d).

A diversidade e a especificidade de conhecimento também se manifestaram no significativo número de participantes de formação/ ocupação na área de ciências biológicas $(33,78 \%)$ e na área de ciências sociais e humanas $(34,06 \%)$ (Abrasco, 2000d).

\section{Congresso Brasileiro de CiênCias Sociais e Humanas EM SAÚDE}

O III Congresso Brasileiro de Ciências Sociais e Humanas em Saúde, promovido pela Abrasco, tendo como tema central os "Desafios da fragilidade da vida na sociedade contemporânea", realiza-se no período de 9 a 13 de julho de 2005, em Florianópolis (SC), contando com Paulo Ernani Gadelha Vieira como presidente da associação e Madel Terezinha Luz como a presidente do evento.

Para a entidade, o tema central respondeu "à necessidade de uma reflexão articulada no campo das ciências sociais e humanas (CSH) sobre a saúde e a qualidade de vida das populações" (Abrasco, 2004c:16).

O congresso é destaque no boletim 94 da associação, a qual afirma em seu editorial que a realização do evento "permitirá que de maneira 
sólida e consistente avancemos na compreensão da determinação social, econômica e política do processo saúde-doença" (Abrasco, 2005:2).

$\mathrm{O}$ congresso ocorre num momento em que a

dinamização da área de Ciências Sociais e Humanas (CSH) em Saúde, face ao seu crescimento notável, é marcada pelo volume e qualidade de suas pesquisas e publicações envolvendo as questões da Saúde Coletiva. É objetivo deste Congresso a disseminação e reconhecimento da produção das ciências humanas e sociais em saúde no conjunto das regiões do país. (Abrasco, 2004c:17)

O evento demonstra a vitalidade da área dando um salto em relação ao segundo congresso realizado, contando com a participação de cerca de 1.800 pessoas e mais de dois mil trabalhos.

\section{CONSIDERAÇÕES FinAis}

Como se viu, a crescente capacidade convocatória e mobilizadora da Abrasco mantém-se ao longo dos 25 anos de atividades da associação, sendo que seus congressos apresentam-se como fóruns de divulgação da produção científica do campo, de difusão de conhecimentos, de troca e de relatos de experiências, de tomadas de posição, de posicionamentos e de proposições políticas. Para Noronha (2003:5), os congressos da Abrasco são "celebrações de conquistas, reencontros, companheirismos, trocas de conhecimentos e experiências, renovação dos compromissos". Os congressos apresentam-se também como palco de demonstração de especificidades, refletindo a diversidade e a pluralidade inerentes ao campo da Saúde Coletiva e, conseqüentemente, à associação.

Desde o primeiro evento realizado, observa-se um crescente knowhow adquirido pela associação na promoção desses eventos com o estabelecimento de variadas parcerias, ao mesmo tempo que se notam as progressivas complexidade e abrangência do campo, expressas nas mais variadas temáticas.

Assim, verifica-se que os congressos, numa ousadia organizacional e temática, vão progressivamente incluindo novas questões com perspectivas ampliadas de discussão, discussões essas advindas do fato de ser a saúde resultante do estilo de vida - questões afeitas ao ambiente, às situações de fragilização da vida e à incorporação do paradigma da promoção da saúde, dentre outras. No que se refere à organização, identificase também a introdução de algumas inovações em eventos mais recentes, ampliando as possibilidades de participação neles. 
As dimensões alcançadas nos últimos congressos, com o número crescente de trabalhos e profissionais inscritos, têm levado a Abrasco a repensar constantemente os aspectos organizacionais e representativos do 'Abrascão'. Entre outras propostas, considera-se necessária a realização de eventos de caráter regionalizado no sentido de propiciar maior participação de profissionais e instituições dos diversos estados e regiões do país, assim como de profissionais inseridos nos serviços de saúde.

Outro desafio refere-se à inserção internacional da associação, processo em curso e que pode ser visto como um vôo que certamente alcançará altitudes mais elevadas.

Repensar essas e outras questões se apresenta como mais um desafio a ser enfrentado não só pelas diretorias da Abrasco, mas também por todo o conjunto de seus associados.

\section{REFERÊNCIAS BIBLIOGRÁFICAS}

ABRASCO. CONGRESSO BRASILEIRO DE SAÚDE COLETIVA, I, 1986, Rio de Janeiro. Anais... Rio de Janeiro: Abrasco, 1986a.

ABRASCO. Declaração Final do I Congresso Brasileiro de Saúde Coletiva. Boletim da Associação Brasileira de Pós-Graduação em Saúde Coletiva, 19, ano V, jul.set.1986b.

ABRASCO. Carta de São Paulo. In: CONGRESSO BRASILEIRO DE SAÚDE COLETIVA, II; CONGRESSO PAULISTA DE SAÚDE PÚBLICA, III, 1989, São Paulo. São Paulo: Abrasco, 1989a. (Mimeo.)

ABRASCO. CONGRESSO BRASILEIRO DE SAÚDE COLETIVA, II; CONGRESSO PAULISTA DE SAÚDE PÚBLICA, III, 1989, São Paulo. Programa. São Paulo: Abrasco, $1989 \mathrm{~b}$.

ABRASCO. CONGRESSO BRASILEIRO DE EPIDEMIOLOGIA, I, 1990, Campinas. Anais... Campinas, São Paulo: Abrasco, 1990.

ABRASCO. Boletim da Associação Brasileira de Pós-Graduação em Saúde Coletiva, 47, ano X, jul.-set.1992a.

ABRASCO. Carta de Porto Alegre. In: CONGRESSO BRASILEIRO DE SAÚDE COLETIVA, III; ENCONTRO DE SAÚDE COLETIVA DO CONE SUL, I, 1992, Porto Alegre. Fôlder. Porto Alegre: Abrasco, 1992b.

ABRASCO. CONGRESSO BRASILEIRO DE SAÚDE COLETIVA, III; ENCONTRO DE SAÚDE COLETIVA DO CONE SUL, I, 1992, Porto Alegre. Programa. Porto Alegre: Abrasco, 1992c.

ABRASCO. CONGRESSO BRASILEIRO DE EPIDEMIOLOGIA, II, 1992, Belo Horizonte. Programa e Resumos. Belo Horizonte: Coopmed, 1992d.

ABRASCO. ENCONTRO BRASILEIRO DE CIÊNCIAS SOCIAIS EM SAÚDE, I, 1993, Belo Horizonte. Anais... Belo Horizonte: Abrasco, 1993. 
ABRASCO. Carta de Pernambuco. In: CONGRESSO BRASILEIRO DE SAÚDE COLETIVA, IV, 1994, Olinda. Olinda, Pernambuco: Abrasco, 1994a.

ABRASCO. CONGRESSO BRASILEIRO DE SAÚDE COLETIVA, IV, 1994, Olinda. Programa. Olinda, Pernambuco: Abrasco, 1994b.

ABRASCO. Boletim da Associação Brasileira de Pós-Graduação em Saúde Coletiva Especial, 54, ano XII, ago.-set.1994c.

ABRASCO. Boletim da Associação Brasileira de Pós-Graduação em Saúde Coletiva Especial, 57, ano XIII, jul.1995a.

ABRASCO. Carta de Salvador. Boletim da Associação Brasileira de Pós-Graduação em Saúde Coletiva Especial, 57, ano XIII, jul.1995b.

ABRASCO. Carta de Curitiba. Boletim da Associação Brasileira de Pós-Graduação em Saúde Coletiva, 59, ano XIII, nov.-dez.1995c.

ABRASCO. CONGRESSO BRASILEIRO DEEPIDEMIOLOGIA, III; CONGRESSO IBEROAMERICANO, II; CONGRESSO LATINO-AMERICANO, I; MOSTRA DE TECNOLOGIA EM EPIDEMIOLOGIA-EPITEC, I, 1995, Salvador. Programa Final. Salvador: Abrasco, 1995d.

ABRASCO. CONGRESSO BRASILEIRO DE SAÚDE COLETIVA, V; CONGRESSO PAULISTA DE SAÚDE PÚBLICA, V, 1997, Águas de Lindóia. Anais... Águas de Lindóia, São Paulo: Abrasco, 1997a.

ABRASCO. CONGRESSO BRASILEIRO DE SAÚDE COLETIVA, V; CONGRESSO PAULISTA DE SAÚDE PÚBLICA, V, 1997, Águas de Lindóia. Programa. Águas de Lindóia, São Paulo: Abrasco, 1997b.

ABRASCO. CONGRESSO BRASILEIRO DE SAÚDE COLETIVA, V; CONGRESSO PAULISTA DE SAÚDE PÚBLICA, V, 1997, Águas de Lindóia. Resumos. Águas de Lindóia, São Paulo: Abrasco, 1997c.

ABRASCO. Boletim da Associação Brasileira de Pós-Graduação em Saúde Coletiva Especial, 70, ano XVI, jul.-set.1998a.

ABRASCO. CONGRESSO BRASILEIRO DE EPIDEMIOLOGIA, IV, 1998, Rio de Janeiro. Programa. Rio de Janeiro: Abrasco, 1998b.

ABRASCO. CONGRESSO BRASILEIRO DE CIÊNCIAS SOCIAIS EM SAÚDE, II, 1999, São Paulo. Livro de Resumos. São Paulo: Abrasco, 1999.

ABRASCO. CONGRESSO BRASILEIRO DE SAÚDE COLETIVA, VI, 2000, Salvador. Boletim 1. Salvador: Abrasco, 2000a.

ABRASCO. CONGRESSO BRASILEIRO DE SAÚDE COLETIVA, VI, 2000, Salvador. Fôlder. Salvador: Abrasco, 2000b.

ABRASCO. CONGRESSO BRASILEIRO DE SAÚDE COLETIVA, VI, 2000, Salvador. Programa. Salvador: Abrasco, 2000c.

ABRASCO. CONGRESSO BRASILEIRO DE CIÊNCIAS SOCIAIS EM SAÚDE, II, 1999 , São Paulo. Relatório Final. São Paulo: Abrasco, 2000d.

ABRASCO. Boletim da Associação Brasileira de Pós-Graduação em Saúde Coletiva, 81, ano XVIII, abr.-jun.2001.

ABRASCO. Boletim da Associação Brasileira de Pós-Graduação em Saúde Coletiva, 84, ano XIX, jan.-abr.2002a. 
ABRASCO. Saúde, justiça, cidadania: todos ao VII Congresso Brasileiro de Saúde Coletiva. Boletim da Associação Brasileira de Pós-Graduação em Saúde Coletiva, 85, ano XIX, maio-ago.2002b.

ABRASCO. Boletim da Associação Brasileira de Pós-Graduação em Saúde Coletiva Especial do VII Congresso Brasileiro de Saúde Coletiva, 88, ano XX, maio-set.2003a.

ABRASCO. CONGRESSO BRASILEIRO DE SAÚDE COLETIVA, VII, 2003, Rio de Janeiro. Livro de Resumos, 1(8), suplemento 1. Rio de Janeiro: Abrasco, 2003b.

ABRASCO. Editorial. Boletim da Associação Brasileira de Pós-Graduação em Saúde Coletiva, 90, ano XXI, mai.2004a.

ABRASCO. Boletim da Associação Brasileira de Pós-Graduação em Saúde Coletiva, 91, ano XXI, ago.2004b.

ABRASCO. Boletim da Associação Brasileira de Pós-Graduação em Saúde Coletiva, 92, ano XXI, nov.2004c.

ABRASCO. Boletim da Associação Brasileira de Pós-Graduação em Saúde Coletiva, 94, ano XXI, jun.2005a.

ABRASCO. Boletim da Associação Brasileira de Pós-Graduação em Saúde Coletiva, 95, ano XXI, dez.2005b.

BARATA, R. de C. B. Discurso de abertura. In: ABRASCO. CONGRESSO BRASILEIRO DE SAÚDE COLETIVA, V; CONGRESSO PAULISTA DE SAÚDE PÚBLICA, V, 1997, Águas de Lindóia. Anais... Águas de Lindóia, São Paulo: Abrasco, 1997.

BARATA, R. de C. B. In: Boletim do VI Congresso Brasileiro de Saúde Coletiva, 1. Salvador: Abrasco, maio.2000.

BARRETO, M. Discurso de abertura dos Congressos de Epidemiologia. Boletim da Associação Brasileira de Pós-Graduação em Saúde Coletiva Especial, 57, ano XIII, jul.1995.

BELISÁRIO, S. A. Associativismo em Saúde Coletiva: um estudo da Associação Brasileira de Pós-Graduação em Saúde Coletiva - Abrasco, 2002. Tese de Doutorado em Saúde Coletiva, Campinas: Faculdade de Ciências Médicas/Universidade Estadual de Campinas (Unicamp). (Mimeo.)

CANESQUI, A. M. Discurso de abertura do I Congresso Brasileiro de Ciências Sociais em Saúde. Boletim da Associação Brasileira de Pós-Graduação em Saúde Coletiva, 59, ano XIII, nov.-dez.1995.

FERREIRA, A. B. de H. Dicionário Aurélio Básico da Língua Portuguesa. Rio de Janeiro: Nova Fronteira, 1986.

GOLDBAUM, M. In: Boletim da Associação Brasileira de Pós-Graduação em Saúde Coletiva, 80, ano XVIII, jan.-mar.2001.

GUEDES, J. da S. Discurso de abertura. Boletim da Associação Brasileira de PósGraduação em Saúde Coletiva Especial, 40, ano IX, set.1990.

KOIFMAN, S. Discurso de abertura do EPIRIO-98. Boletim da Associação Brasileira de Pós-Graduação em Saúde Coletiva Especial, 70, ano XVI, jul.-set.1998.

LOUREIRO, S. Discurso de Sebastião Loureiro no I Congresso Brasileiro de Saúde Coletiva. Boletim da Associação Brasileira de Pós-Graduação em Saúde Coletiva, 19, ano V, jul.-set.1986. 
LUDERMIR, A. B. Discurso de abertura. In: CONGRESSO BRASILEIRO DE EPIDEMIOLOGIA, VI, 2004, Recife. Recife: Abrasco, 2004. 1 CD-ROM.

NASCIMENTO, A. Saúde é responsabilidade do Estado contemporâneo. Revista Tema, 15:2, Programa Radis, out.1997.

NORONHA, J.C. de. In: ABRASCO. CONGRESSO BRASILEIRO DE SAÚDE COLETIVA, VII, 2003, Rio de Janeiro. Livro de Resumos, 1(8), suplemento 1. Rio de Janeiro: Abrasco, 2003.

NORONHA, J. C. de. O Congresso Mundial de Saúde Pública e a atuação internacional da Abrasco. Boletim da Associação Brasileira de Pós-Graduação em Saúde Coletiva, 93, ano XXI, abr.2005.

PAIM, J. In: CONGRESSO BRASILEIRO DE SAÚDE COLETIVA, VI, 2000, Salvador. Boletim 1. Salvador: Abrasco, maio.2000.

SIQUEIRA, B. P. de. In: Boletim da Associação Brasileira de Pós-Graduação em Saúde Coletiva, 7, ano II, maio-jul.1983.

SOUZA, A. F. G. de. Conferência de abertura: "Desafios às ciências sociais na área da saúde”. In: ENCONTRO BRASILEIRO DE CIÊNCIAS SOCIAIS EM SAÚDE, I, 1993, Belo Horizonte. Anais... Belo Horizonte: Abrasco, 1993.

TEMA. Saúde é responsabilidade do Estado contemporâneo. Rio de Janeiro: Programa Radis, 15, out.1997 (número especial da revista dedicado ao V CBSC, realizado em 1997).

TEMA. Epidemiologia da esperança. Rio de Janeiro: Programa Radis, 16, out.1998 (número especial da revista dedicado ao IV Congresso Brasileiro de Epidemiologia).

Demais Fontes Consultadas

ABRASCO. Boletim 1, ano I, jan.-mar.1982, a Boletim 95, ano XXI, dez.2005. 



\section{QuAdro-Resumo dos Congressos}

\begin{tabular}{|c|c|c|c|c|c|c|}
\hline Evento & Período & Local & $\begin{array}{l}\text { Número de } \\
\text { participantes }\end{array}$ & Tema & $\begin{array}{l}\text { Presidente da } \\
\text { Abrasco }\end{array}$ & Estrutura do evento \\
\hline $\begin{array}{l}\text { I Congresso Nacional da } \\
\text { Abrasco/ } \\
\text { II Congresso Paulista de } \\
\text { Saúde Pública }\end{array}$ & $\begin{array}{l}17 a \\
21 / 4 / 1983\end{array}$ & $\begin{array}{l}\text { São Paulo } \\
\text { (SP) }\end{array}$ & 2.000 & "A política nacion al de saúde" & $\begin{array}{l}\text { Benedictus } \\
\text { Philadelpho de } \\
\text { Siqueira }\end{array}$ & 26 temas específicos \\
\hline $\begin{array}{l}\text { I Congresso Brasileiro de } \\
\text { Saúde Coletiva }\end{array}$ & $\begin{array}{l}22 \mathrm{a} \\
26 / 9 / 1986\end{array}$ & $\begin{array}{l}\text { Rio de } \\
\text { Janeiro (RJ) }\end{array}$ & 2.000 & $\begin{array}{l}\text { "Reforma Sanitária: garantia do direito } \\
\text { universal à saúde" }\end{array}$ & Sebastião Loureiro & $\begin{array}{l}15 \text { comunicações } \\
\text { coordenadas } \\
9 \text { mesas-redondas } \\
2 \text { conferências } \\
20 \text { cursos } \\
15 \text { sessões temas livres }\end{array}$ \\
\hline $\begin{array}{l}\text { II Congresso Brasileiro de } \\
\text { Saúde Coletiva/ } \\
\text { III Congresso Paulista de } \\
\text { Saúde Pública }\end{array}$ & $\begin{array}{l}3 \mathrm{a} \\
7 / 7 / 1989\end{array}$ & $\begin{array}{l}\text { São Paulo } \\
\text { (SP) }\end{array}$ & 2.500 & $\begin{array}{l}\text { "Sistema Único de Saúde: uma } \\
\text { conquista da sociedade" }\end{array}$ & $\begin{array}{l}\text { Guilherme } \\
\text { Rodrigues da Silva }\end{array}$ & $\begin{array}{l}4 \text { mesas-redondas } \\
16 \text { cursos } \\
20 \text { comunicações } \\
\text { coordenadas } \\
15 \text { temas livres }\end{array}$ \\
\hline $\begin{array}{l}\text { III Congresso Brasileiro de } \\
\text { Saúde Coletiva/ } \\
\text { I Encontro de Saúde } \\
\text { Coletiva do Cone Sul }\end{array}$ & $\begin{array}{l}16 \mathrm{a} \\
20 / 5 / 1992\end{array}$ & $\begin{array}{l}\text { Porto } \\
\text { Alegre (RS) }\end{array}$ & $\begin{array}{l}\text { (dados não } \\
\text { encontrados) }\end{array}$ & "Saúde como direito à vida" & $\begin{array}{l}\text { Arlindo Fábio } \\
\text { Gómez de Sousa }\end{array}$ & $\begin{array}{l}2 \text { conferências } \\
6 \text { mesas-redondas } \\
20 \text { palestras } \\
5 \text { comunicações } \\
\text { coordenadas } \\
16 \text { cursos } \\
5 \text { oficinas }\end{array}$ \\
\hline $\begin{array}{l}\text { IV Congresso Brasileiro de } \\
\text { Saúde Coletiva }\end{array}$ & $\begin{array}{l}19 \mathrm{a} \\
23 / 6 / 1994\end{array}$ & Olinda (PE) & 3.800 & "Saúde: o feito por fazer" & $\begin{array}{l}\text { Arlindo Fábio } \\
\text { Gómez de Sousa }\end{array}$ & $\begin{array}{l}14 \text { oficinas } \\
15 \text { cursos } \\
3 \text { conferências magnas } \\
28 \text { palestras } \\
6 \text { mesas-redondas } \\
36 \text { painéis } \\
76 \text { comunicações } \\
\text { coordenadas }\end{array}$ \\
\hline
\end{tabular}




\begin{tabular}{|c|c|c|c|c|c|c|}
\hline Evento & Período & Local & $\begin{array}{l}\text { Número de } \\
\text { participantes }\end{array}$ & Tema & $\begin{array}{l}\text { Presidente da } \\
\text { Abrasco }\end{array}$ & $\begin{array}{l}\text { Estrutura do } \\
\text { evento }\end{array}$ \\
\hline $\begin{array}{l}\text { V Congresso Brasileiro de } \\
\text { Saúde Coletiva/ } \\
\text { V Congresso Paulista de } \\
\text { Saúde Pública }\end{array}$ & $\begin{array}{l}25 \mathrm{a} \\
29 / 8 / 1997\end{array}$ & $\begin{array}{l}\text { Águas de } \\
\text { Lindóia } \\
\text { (SP) }\end{array}$ & 2.500 & $\begin{array}{l}\text { "Saúde: responsabilidade do Estado } \\
\text { contemporâneo" }\end{array}$ & $\begin{array}{l}\text { Rita de Cássia } \\
\text { Barradas Barata }\end{array}$ & $\begin{array}{l}17 \text { cursos } \\
15 \text { oficinas } \\
3 \text { conferências } \\
6 \text { mesas-redondas } \\
34 \text { palestras e debates } \\
41 \text { painéis } \\
120 \text { comunicações } \\
\text { coordenadas }\end{array}$ \\
\hline $\begin{array}{l}\text { VI Congresso Brasileiro de } \\
\text { Saúde Coletiva }\end{array}$ & $\begin{array}{l}28 / 8 \text { a } \\
1^{\circ} / 9 / 2000\end{array}$ & $\begin{array}{l}\text { Salvador } \\
\text { (BA) }\end{array}$ & 5.000 & "O sujeito na Saúde Coletiva" & $\begin{array}{l}\text { Rita de Cássia } \\
\text { Barradas Barata }\end{array}$ & $\begin{array}{l}19 \text { cursos } \\
16 \text { oficinas } \\
46 \text { mesas-redondas } \\
9 \text { grandes debates }\end{array}$ \\
\hline $\begin{array}{l}\text { VII Congresso Brasileiro de } \\
\text { Saúde Coletiva }\end{array}$ & $\begin{array}{l}29 / 7 \mathrm{a} \\
2 / 8 / 2003\end{array}$ & $\begin{array}{l}\text { Brasilia } \\
\text { (DF) }\end{array}$ & 8.000 & "Saúde, justiça, cidadania" & $\begin{array}{l}\text { José Carvalho de } \\
\text { Noronha }\end{array}$ & $\begin{array}{l}159 \text { comunicações } \\
\text { coordenadas } \\
127 \text { painéis } \\
26 \text { oficinas } \\
29 \text { palestras } \\
13 \text { colóquios } \\
9 \text { grandes debates } \\
3 \text { conferências } \\
\text { magnas }\end{array}$ \\
\hline $\begin{array}{l}\text { VIII Congresso Brasileiro } \\
\text { de Saúde Coletiva/ } \\
\text { XI Congresso Mundial de } \\
\text { Saúde Pública }\end{array}$ & $\begin{array}{l}21 \mathrm{a} \\
25 / 8 / 2006\end{array}$ & $\begin{array}{l}\text { Rio de } \\
\text { Janeiro }\end{array}$ & $\begin{array}{l}\text { (dados em } \\
\text { sistematização) }\end{array}$ & $\begin{array}{l}\text { "Saúde Coletiva em um mundo } \\
\text { globalizado: rompendo barreiras sociais, } \\
\text { econômicas e políticas" }\end{array}$ & $\begin{array}{l}\text { Paulo Ernani Gadelha } \\
\text { Vieira }\end{array}$ & $\begin{array}{l}\text { (dados em } \\
\text { sistematização) }\end{array}$ \\
\hline $\begin{array}{l}\text { I Congresso Brasileiro de } \\
\text { Epidemiologia }\end{array}$ & $\begin{array}{l}2 \mathrm{a} \\
6 / 9 / 1990\end{array}$ & $\begin{array}{l}\text { Campinas } \\
(\mathrm{SP})\end{array}$ & 1.500 & $\begin{array}{l}\text { "Epidemiologia e desigualdade social: } \\
\text { os desafios do final do século" }\end{array}$ & José da Silva Guedes & $\begin{array}{l}15 \text { cursos } \\
5 \text { oficinas } \\
5 \text { conferências } \\
6 \text { mesas-redondas } \\
45 \text { comunicações } \\
\text { coordenadas } \\
233 \text { pôsteres }\end{array}$ \\
\hline $\begin{array}{l}\text { II Congresso Brasileiro de } \\
\text { Epidemiologia }\end{array}$ & $\begin{array}{l}13 \mathrm{a} \\
17 / 7 / 1992\end{array}$ & $\begin{array}{l}\text { Belo } \\
\text { Horizonte } \\
(\mathrm{MG})\end{array}$ & 2.000 & $\begin{array}{l}\text { "Qualidade de vida: compromisso } \\
\text { histórico da epidemiologia" }\end{array}$ & $\begin{array}{l}\text { Arlindo Fábio Gómez } \\
\text { de Sousa }\end{array}$ & $\begin{array}{l}5 \text { oficinas } \\
22 \text { cursos } \\
6 \text { mesas-redondas } \\
17 \text { palestras } \\
3 \text { conferências }\end{array}$ \\
\hline $\begin{array}{l}\text { III Congresso Brasileiro de } \\
\text { Epidemiologia/ } \\
\text { II Congresso Ibero- } \\
\text { Americano de } \\
\text { Epidemiologia/ } \\
\text { I Congresso Latino- } \\
\text { Americano de } \\
\text { Epidemiologia/ } \\
\text { I Mostra de Tecnologia em } \\
\text { Epidemiologia }\end{array}$ & $\begin{array}{l}24 \mathrm{a} \\
28 / 4 / 1995\end{array}$ & $\begin{array}{l}\text { Salvador } \\
\text { (BA) }\end{array}$ & 3.500 & $\begin{array}{l}\text { "A epidemiologia na busca da equidade } \\
\text { em saúde" }\end{array}$ & $\begin{array}{l}\text { Maria Cecília de Souza } \\
\text { Minayo }\end{array}$ & $\begin{array}{l}22 \text { cursos } \\
6 \text { oficinas } \\
1.145 \text { pôsteres } \\
89 \text { comunicações } \\
\text { coordenadas } \\
4 \text { conferências } \\
6 \text { mesas-redondas } \\
32 \text { painéis } \\
48 \text { palestras }\end{array}$ \\
\hline
\end{tabular}




\begin{tabular}{|c|c|c|c|c|c|c|}
\hline Evento & Periodo & Local & $\begin{array}{l}\text { Número de } \\
\text { participantes }\end{array}$ & Tema & $\begin{array}{l}\text { Presidente da } \\
\text { Abrasco }\end{array}$ & Estrutura do evento \\
\hline $\begin{array}{l}\text { IV Congresso } \\
\text { Brasileiro de } \\
\text { Epidemiologia/ } \\
\text { EPIRIO-98 }\end{array}$ & $\begin{array}{l}28 / 9 a \\
1^{0} / 10 / 1998\end{array}$ & $\begin{array}{l}\text { Rio de } \\
\text { Janeiro } \\
\text { (RJ) }\end{array}$ & 2.000 & $\begin{array}{l}\text { "Epidemiologia em perspectiva: novos } \\
\text { tempos, pessoas e lugares" }\end{array}$ & $\begin{array}{l}\text { Rita de Cássia } \\
\text { Barradas Barata }\end{array}$ & $\begin{array}{l}57 \text { painéis } \\
15 \text { palestras } \\
6 \text { mesas-redondas } \\
6 \text { conferências } \\
7 \text { oficinas } \\
14 \text { cursos }\end{array}$ \\
\hline $\begin{array}{l}\text { V Congresso } \\
\text { Brasileiro de } \\
\text { Epidemiologia }\end{array}$ & $\begin{array}{l}23 \mathrm{a} \\
27 / 3 / 2002\end{array}$ & $\begin{array}{l}\text { Curitiba } \\
\text { (PR) }\end{array}$ & $\begin{array}{l}\text { (dados não } \\
\text { encontrados) }\end{array}$ & "A epidemiologia na promoção da saúde" & $\begin{array}{l}\text { José Carvalho de } \\
\text { Noronha }\end{array}$ & $\begin{array}{l}10 \text { oficinas } \\
26 \text { cursos } \\
4 \text { conferências } \\
6 \text { mesas-redondas } \\
46 \text { palestras } \\
44 \text { painéis } \\
7 \text { colóquios } \\
1.693 \text { pôsteres }\end{array}$ \\
\hline $\begin{array}{l}\text { VI Congresso } \\
\text { Brasileiro de } \\
\text { Epidemiologia }\end{array}$ & $\begin{array}{l}19 \mathrm{a} \\
23 / 6 / 2004\end{array}$ & $\begin{array}{l}\text { Recife } \\
(\mathrm{PE})\end{array}$ & 4.000 & "Um olhar sobre a cidade" & Moisés Goldbaum & $\begin{array}{l}446 \text { comunicações } \\
\text { coordenadas } \\
97 \text { painéis } \\
43 \text { palestras } \\
2.936 \text { pôsteres }\end{array}$ \\
\hline $\begin{array}{l}\text { I Encontro } \\
\text { Brasileiro de } \\
\text { Ciências Sociais em } \\
\text { Saúde }\end{array}$ & $\begin{array}{l}28 / 9 \text { a } \\
1^{2 / 10 / 1993}\end{array}$ & $\begin{array}{l}\text { Belo } \\
\text { Horizon- } \\
\text { te (MG) }\end{array}$ & 220 & (sem tema definido) & $\begin{array}{l}\text { Arlindo Fábio } \\
\text { Gómez de Sousa }\end{array}$ & $\begin{array}{l}4 \text { cursos } \\
5 \text { oficinas } \\
3 \text { painéis } \\
2 \text { mesas-redondas }\end{array}$ \\
\hline $\begin{array}{l}\text { I Congresso } \\
\text { Brasileiro de } \\
\text { Ciências Sociais em } \\
\text { Saúde }\end{array}$ & $\begin{array}{l}7 \mathrm{a} \\
10 / 11 / 1995\end{array}$ & $\begin{array}{l}\text { Curitiba } \\
\text { (PR) }\end{array}$ & 500 & "Cidade e saúde" & $\begin{array}{l}\text { Maria Cecilia de } \\
\text { Souza Minayo }\end{array}$ & $\begin{array}{l}3 \text { conferências } \\
6 \text { palestras } \\
6 \text { mesas-redondas } \\
11 \text { cursos } \\
43 \text { comunicações } \\
\text { coordenadas } \\
231 \text { pôsteres }\end{array}$ \\
\hline $\begin{array}{l}\text { II Congresso } \\
\text { Brasileiro de } \\
\text { Ciências Sociais em } \\
\text { Saúde }\end{array}$ & $\begin{array}{l}7 \mathrm{a} \\
10 / 12 / 1999\end{array}$ & $\begin{array}{l}\text { São Paulo } \\
\text { (SP) }\end{array}$ & 578 & $\begin{array}{l}\text { "Ciências Sociais e saúde: tendências, objetos, } \\
\text { abordagens" }\end{array}$ & $\begin{array}{l}\text { Rita de Cássia } \\
\text { Barradas Barata }\end{array}$ & $\begin{array}{l}54 \text { comunicações } \\
\text { coordenadas com } 256 \\
\text { trabalhos } \\
7 \text { cursos } \\
9 \text { mesas-redondas } \\
3 \text { conferências } \\
181 \text { pôsteres }\end{array}$ \\
\hline $\begin{array}{l}\text { III Congresso } \\
\text { Brasileiro de } \\
\text { Ciências Sociais e } \\
\text { Humanas em Saúde }\end{array}$ & $\begin{array}{l}9 \mathrm{a} \\
13 / 7 / 2005\end{array}$ & $\begin{array}{l}\text { Florianó- } \\
\text { polis (SC) }\end{array}$ & 1.800 & $\begin{array}{l}\text { "Desafios da fragilidade da vida na sociedade } \\
\text { contemporânea" }\end{array}$ & $\begin{array}{l}\text { Paulo Ernani } \\
\text { Gadelha Vieira }\end{array}$ & $\begin{array}{l}3 \text { conferências magnas } \\
9 \text { mesas- redondas } \\
2.032 \text { trabalhos } \\
\text { aprovados - } \\
443 \text { para apresentação } \\
\text { oral } \\
1.589 \text { pôsteres } \\
10 \text { oficinas temáticas }\end{array}$ \\
\hline
\end{tabular}




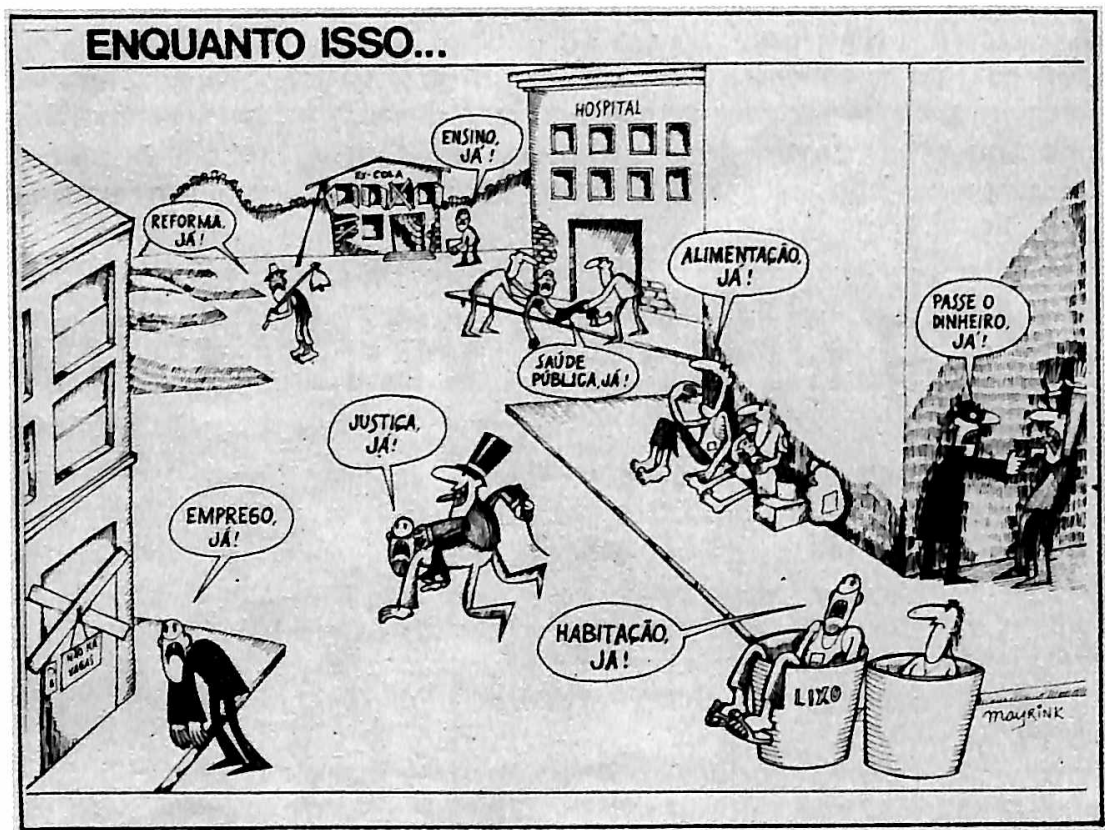

Imagem 7 - Charge de Mayrink. Quebra-nós. Brasilia: A. Quice, 1984.

Charge publicada no Boletim Abrasco, 13, nov.-dez. 1984. p.I.

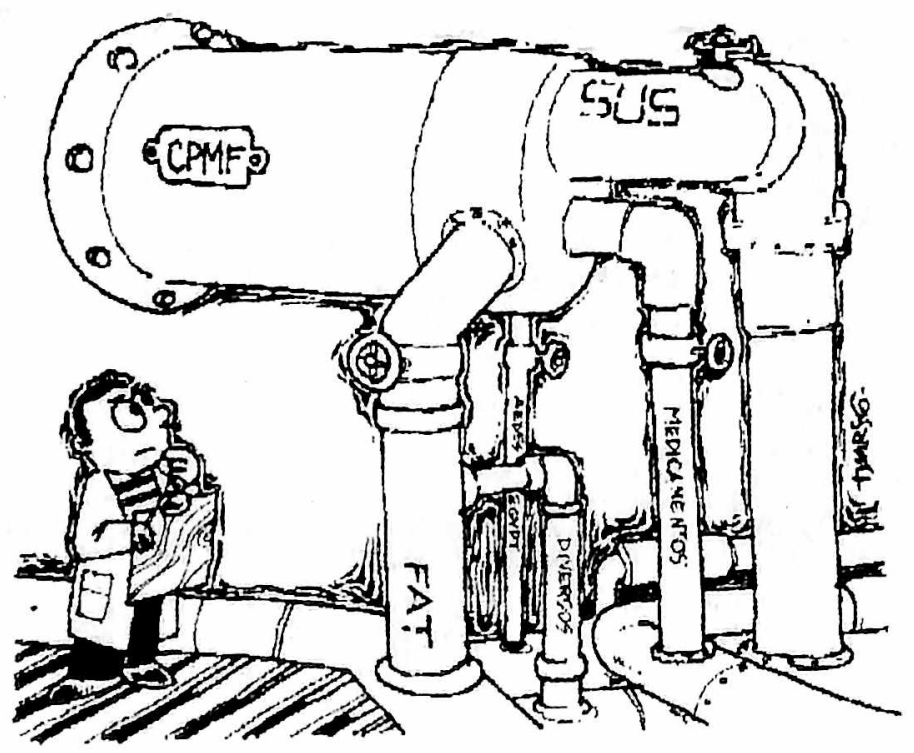

Imagem 8 - Charge de Tibúrcio. Referente ao artigo "Financiamento do setor de saúde na execução". Publicada no Boletim Abrasco, 65, abr.-jun. 1997. 